\title{
Mediating effects of social support between antenatal depression and fear of childbirth among nulliparous woman
}

\author{
Xiao-Lan Zhou ${ }^{1,2}$, Hua Liu' ${ }^{2}$ Xiao-Hong Li $^{2}$, Fei Li ${ }^{2}$, Su-Mei Zhang ${ }^{2}$, Shao-Ru Zhang ${ }^{1}$ \\ ${ }^{1}$ School of Nursing, Xi'an Jiaotong University, Xi'an, China; ${ }^{2}$ School of Nursing, Xi'an Medical University, Xi'an, China \\ Contributions: (I) Conception and design: SR Zhang, XL Zhou; (II) Administrative support: XL Zhou; (III) Provision of study materials or patients: \\ XL Zhou, H Liu; (IV) Collection and assembly of data: XH Li, SM Zhang; (V) Data analysis and interpretation: XL Zhou; (VI) Manuscript writing: \\ All authors; (VII) Final approval of manuscript: All authors. \\ Correspondence to: Shao-Ru Zhang, PhD, Professor. School of Nursing, Xi'an Jiaotong University, 76 Yanta West Road, Xi'an 710061, China. \\ Email: shaoru1958@126.com.
}

Background: Although gestation and childbirth are progressive physical processes for most pregnant
women, there are both physical and great psychosocial challenges throughout the process, which increase
the sensitivity and vulnerability of women. Even for women with low-risk pregnancies, it is common to
experience degrees of fear, especially for primipara women when faced with childbirth. During their first
pregnancy, women may have no relevant health knowledge or experience with delivery and have difficulty
identifying prenatal depression and other existing mental health factors; a fear of childbirth (FOC) may
engender adverse outcomes for mothers and babies. Social support is a very important influential factor for
prenatal depression.

Methods: This study adopted a descriptive cross-sectional design. The participant cohort involved 609 primipara women ( $\geq 18$ years old) who had received routine prenatal care and visited a tertiary care hospital in Xi'an. The participants completed structured questionnaires, including the 10-item Edinburgh Postnatal Depression Scale (EPDS), 12-item Multidimensional Scale of Perceived Social Support (MSPSS), and 33-item Wijma Delivery Expectancy/Experience Questionnaire (W-DEQ), alongside contribution of information regarding their demographic characteristics. Descriptive and correlation analyses were adopted to verify the correlations among these variables. Multiple regression models were examined by the SPSS PROCESS procedure with bootstrapping to confirm the significance of the mediation effect.

Results: The widespread prevalence of FOC in healthy pregnant women was $22.3 \%$ (WDEQ score $\geq 85$ ). The mean scores of depression, social support, as well as FOC scores of participants were 9.50 (5.19), 70.91 (9.25), and 70.43 (20.88), respectively. Remarkable correlations were identified between pregnancy depressive symptoms, social support, and FOC. Results presented an indirect effect, indicating that the impacts of antenatal depression on FOC were mediated by social support.

Conclusions: Perceived social support played a mediating role between antenatal depression and FOC among healthy primipara women. Techniques and suggestions for boosting social support may be expected to have a positive impact on the depressive symptoms of pregnant women with FOC.

Keywords: Mediation; fear of childbirth (FOC); social support; antenatal depression; pregnant women

Submitted Mar 03, 2021. Accepted for publication May 19, 2021.

doi: 10.21037/apm-21-854

View this article at: http://dx.doi.org/10.21037/apm-21-854

\footnotetext{
$\wedge$ ORCID: 0000-0003-4678-8326.
} 


\section{Introduction}

Fear of childbirth (FOC) is commonly known as negative birth expectations (1). The fear often includes that of injury to the baby, genital tract, or death (2). Symptoms of fear increase in the third trimester, especially if the woman is expecting her first child (3). Severe fear is more frequent in nulliparous than in multiparous women $(4,5)$.

Previous studies have found that FOC complicates $7.6-17.8 \%$ of pregnancies. A systematic review showed that the prevalence of severe FOC (tocophobia) is estimated at $14 \%$ and appears to have increased over recent years (5). Increased prevalence of FOC was shown to be associated with depression during pregnancy (6).

The presence of FOC can result in negative birth outcomes such as labor dystocia, more frequently used of epidural, increased request for elective caesarean section (CS), and obstetric complications $(1,7,8)$. In addition, FOC has been linked to increased fetal heart rate and decreased fetal motility in utero, and it continues to affect infants after birth $(9,10)$.

Psychosocial factors are remarkably associated with FOC and previous studies have revealed that depression is strongly linked to FOC $(6,11)$. Among nulliparous women, FOC was most often present in individuals who were lacking in social support and psychological resources $(12,13)$.

Pregnancy can be a time of joy and positive expectations, but is also a major life event involving both psychological and physiological changes. Antenatal depression is an important social health issue as it could potentially lead to harmful impacts for mothers such as postpartum depression (14), and subsequent adverse outcomes for infants (15). A previous systematic reviews and meta analyses report demonstrated that the percentage of antenatal depression in low- and middle-income countries and areas was about $30 \%$, much lower in high-income countries $(18 \%)$, and that $15 \%$ of pregnant women overall experienced major antenatal depression (16). The prevalence of perinatal depression was found to be $15-20 \%$ in China (17) and primipara was inferred to have an increased risk of perinatal anxiety and depression (18). Antenatal depression and anxiety have been linked to elective caesarean section (19), stillbirth, premature birth, low birth weight, low Apgar scores, and major congenital anomalies (6).

Factors related to antenatal depression include unemployment, marital status, parity, social support, and so on. It has been suggested that social support before and after childbirth is a strong protective factor for perinatal depression and anxiety $(20,21)$. Xie et al. found no significant difference in women's scores of social support prenatally and postnatally (22), but Li et al. found that women's scores of social support during the first week postpartum were higher than in the third trimester (23). Childhood abuse predicted lower levels of social support (24). In fact, childhood abuse has been identified as a particularly strong predictor of depression and anxiety during the antenatal period (25).

Psychosocial education could effectively in reducing stress and improving social support and lessening postpartum depression of primipara's prenatal depression (26).

People with reduced social support are more likely to experience sub-clinical symptoms of depression than those with a rich social support network (27).

Social support has been shown to be beneficial for alleviating psychological distress and to influence adverse medical outcomes. Strong social support is related to increased psychological well-being and positive responses to important life events (28). In times of increased pressure or stress, social support helps to reduce psychological distress, acting as a buffer for both physical and mental health (29).

Several studies have shown that low social support led to higher risk of FOC (12,30-32). Based on the W-DEQ scores, the levels of FOC were classified as low, moderate, high, and severe fear. Pregnant women with higher levels of childbirth fear report worse emotional (i.e., tense, desolate, panic), psychological (i.e., anxiety, depression) and physical health (i.e., high level of pain and/or discomfort; antenatal fatigue) (33). Several factors related to FOC have been reported, including maternal age, parity, gestational age, previous caesarean section, previous adverse perinatal outcome, lack of social support, and low self-esteem (34-36). Stress, anxiety, depression and lack of social support are associated with fear during pregnancy. Severe fear of childbirth was shown to be more common in nulliparous women, in later pregnancy $(35,37)$. Social support is helpful in stressful situations (38); without emotional and social support, women are more prone to experience adverse pregnancy outcomes including preterm birth and perinatal depression $(39,40)$.

Pregnant women with intense FOC can benefit from individualized psychological and obstetrical support (41). A study indicated that the central mitigating factor for FOC is the support received from women's informal networks including their partner, family members, and close friends (42).

Recent studies have shown that pregnant women with antenatal depression have comparatively lower levels of 
social support (43). International researchers have described the relationship between FOC and social support using qualitative research methods $(39,44)$. Although previous studies have described the correlation between each pair of variables, for example depression in pregnancy, social support, and FOC in healthy pregnant women, few studies have explored the relationships between all 3 variables together within this population.

Hence, we examined the effects of social support in order to explore how it might mediate between antenatal depression and FOC. In line with the abovementioned empirical findings, using Process Macro developed by Hayes (2013; www.https://processmacro.org) to analyze the mediation effect, we made the assumptions that: (H1) prenatal depression is associated with FOC; $(\mathrm{H} 2)$ prenatal depression is relevant to perceived social support; (H3) perceived social support is associated with FOC; $(\mathrm{H} 4)$ perceived social support mediates the connection between prenatal depression and FOC.

We present the following article in accordance with the COREQ reporting checklist (available at http://dx.doi. org/10.21037/apm-21-854).

\section{Methods}

\section{Ethical issues}

The ethics review was approved by the Ethics Committee of Xi'an Medical University (XYLS2018170) before the survey. The participants provided written informed consent prior to commencement of the study. All procedures performed in this study involving human participants were in accordance with the Declaration of Helsinki (as revised in 2013).

\section{Study design}

This study employed a descriptive cross-sectional survey.

\section{Participants and settings}

All low-risk nulliparous women in the second and/or third trimester visiting the maternal-infant center of 2 tertiary hospitals in Xi'an (the First Affiliated Hospital of Xi'an Medical University, the Second Affiliated Hospital of Xi'an Medical University), China were recruited as potential participants. All participants were diagnosed based on their medical history and clinical examination, and were filtered for inclusion in the research from June to October 2020 via convenience sampling. Among 800 initially screened patients, 72 declined participation. Thus, 728 pregnant women were included after providing written informed consent. A total of 119 questionnaires were not completed and deleted; 609 women remained, with a valid response rate of $83.7 \%$.

\section{Study procedure}

This study received ethical approval from the university and the participated hospitals. All participants were informed that their participation was entirely voluntary and they could withdraw at any time, which would not affect the quality of their obstetric health services. The data would be kept confidential and, after ethical approval, a pilot tested of 30 qualified participants would be conducted with no problems reported. Researcher and assistant were responsible for data collection and they were trained to ensure the accuracy and consistency of the data collection. All eligible participants were invited to participate in the study while waiting for their appointments at the chosen hospital's obstetric out-patient service. After the consent of the pregnant women was obtained, participants were required to complete the Socio-demographic and Obstetric Questionnaire, Chinese version of EPDS and MSPSS, and WDEQ in the interview room. It took about 25 minutes to complete the questionnaires and were withdrawn on site.

\section{Materials}

\section{Antenatal depression}

The Edinburgh Postnatal Depression Scale (EPDS) was used to assess a woman's level of depression over the most recent 7 days during her perinatal period (45). A Chinese version of the EPDS had been earlier translated by Lee et al. (46), which showed good reliability and validity. This instrument included 10 items, with each item rated on a 4-point Likert scale that ranged from 0 to 3 . The total EPDS score range was 0-30 points; higher scores indicated more severe depressive symptoms. A total score of 13 or more indicates depressive symptoms (45).

\section{Social support}

The Multidimensional Scale of Perceived Social Support (MSPSS) is a self-reported questionnaire developed to assess social support. The original questionnaire was developed in 1988 by Zimet et al. (47). The MSPSS 


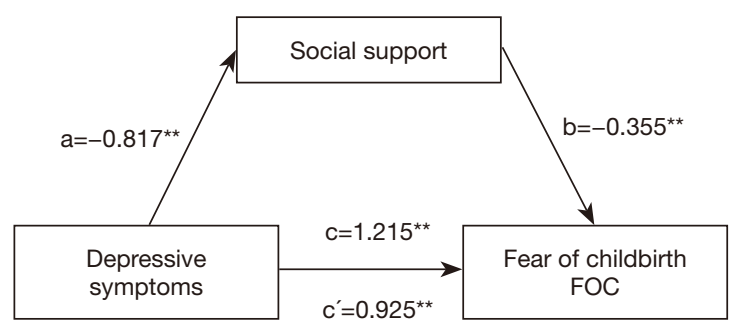

Figure 1 Model of the mediating role of social support between depressive symptoms and FOC. FOC, fear of childbirth. ${ }^{* *} \mathrm{P}<0.01$.

contains 12 items and measures perceived social support from 3 aspects: family, friends, and significant others. Each item is assigned a 7-point Likert scale from 1 (absolutely agree) to 7 (absolutely disagree). The minimum score is 12 points and the maximum score is 84 points. Higher scores suggest a stronger sense of social support. The Cronbach alpha coefficient of the instrument is 0.88 .

\section{FOC}

The level of FOC was measured using the Wijma Delivery Expectancy/Experience Questionnaire (W-DEQ) (48), a self-report measure of FOC. This questionnaire consists of 33 items with a 6-point Likert scale from 0 (not at all) to 5 (extremely). The total score ranges from 0 to 165 . A score $\geq 85$ indicates severe FOC, and a score $\geq 100$ is considered a phobia. In this study, the cut-off point of greater than or equal to 85 was used for fear of childbirth. The questionnaire can be used to compare levels of birth fear between primipara and multipara (48). Based on the W-DEQ scores, the levels of FOC were classified as low [ $\leq 37]$, moderate [38-65], high [66-84], and severe [ $\geq 85]$ (49). The Chinese version of the questionnaire was validated and tested for reliability during the study, revealing a Cronbach's alpha of 0.88 (50). In this study, the WDEQ-A was found to have a Cronbach's alpha coefficient of 0.85 .

\section{Statistical analysis}

Descriptive analysis was adopted during data processing including calculation of frequency, percentage, mean, and standard deviation (SD) of women's characteristics. Differences among these characteristics were analyzed in relation to FOC by independent $t$-test and one-way analysis of variance (ANOVA).

Pearson correlation ( $r$ ) was used to explore the correlation of continuous variables among depressive symptoms, social support, and FOC.

PROCESS mediation analysis was used on the basis of the ordinary least squares regression analysis (51). In this study, the simple mediation analysis was conducted by PROCESS Macro (Model 4) for SPSS, with a 95\% bias-corrected bootstrap confidence interval (CI) using 5,000 bootstrap samples (52). In order to examine the mediation effects of social support on the relationship between depressive symptoms and FOC, we hypothesized a mediation model with depressive symptoms (continuous independent variable), social support (continuous mediator), and FOC (continuous dependent variable) after controlling covariates. Regarding data, firstly, the total effect of having depressive symptoms on FOC was estimated (c path) (Figure 1). Secondly, the direct effect of having depressive symptoms on social support was estimated (a path). Thirdly, the direct effect of social support on FOC was estimated (b path). Lastly, the indirect effect of having depressive symptoms on FOC, mediated by social support, was estimated ( $c^{\prime}$ path). If the bias-corrected bootstrap 95\% CIs of the indirect effect $(\mathrm{a} \times \mathrm{b})$ did not contain 0 , it indicated significant mediation. All statistical analyses were conducted using the software SPSS 24.0 (IBM Corp., Armonk, NY, USA), and a P value less than 0.05 was considered statistically significant.

\section{Results}

\section{Participant socio-demographic and clinical characteristics}

Among 609 Chinese pregnant women who participated in this study, the mean age was 28.47 (SD: 4.26) years old and $586(96.22 \%)$ participants were of Han ethnicity. Around 343 (56.32\%) women had obtained degrees of education above the college level and 220 (36.12\%) resided in rural areas. Moreover, 110 participants $(18.1 \%)$ were white collar workers, while 77 (12.6\%) were low income earners. A total of $136(136 / 609,22 \%)$ primiparous women experienced severe levels of fear (defined as $\geq 85$ scores on the WDEQ-A).

\section{Differences in FOC according to women's characteristics}

The differences in FOC according to women's sociodemographic and clinical characteristics is shown in Table 1. The level of FOC differed significantly according to age ( $\mathrm{F}=3.18, \mathrm{P}=0.024)$, educational level $(\mathrm{t}=4.99, \mathrm{P}=0.002)$, occupation ( $\mathrm{F}=3.25, \mathrm{P}=0.02)$, monthly income $(\mathrm{F}=7.65$, $\mathrm{P}=0.001)$, marital status $(\mathrm{t}=9.84, \mathrm{P}=0.002)$, relationship 
Table 1 Female sociodemographic and clinical characteristics and differences in FOC ( $n=609)$

\begin{tabular}{|c|c|c|c|c|}
\hline Characteristics & $\mathrm{N}(\%)$ & Mean (SD) & $t$ or $\mathrm{F}$ & $P$ value \\
\hline$<24$ & $74(12.15)$ & $73.74(20.15)$ & & \\
\hline $24-29$ & $314(51,56)$ & $71.09(20.75)$ & & \\
\hline $30-35$ & $184(30.21)$ & $69.80(21.02)$ & & \\
\hline Nationality Group & & & 0.25 & 0.617 \\
\hline Han & $586(96.22)$ & $70.34(20.74)$ & & \\
\hline Others & $23(3.78)$ & $72.56(24.43)$ & & \\
\hline Education level & & & 4.99 & 0.002 \\
\hline College & $308(50.57)$ & $68.11(21.87)$ & & \\
\hline Master or above & $35(5.75)$ & $64.11(22.50)$ & & \\
\hline Occupation & & & 3.25 & 0.02 \\
\hline White collar & $110(18.06)$ & $66.26(22.11)$ & & \\
\hline Blue collar & $159(26.11)$ & $68.52(20.09)$ & & \\
\hline Freelancer & $247(40.56)$ & $72.77(21.54)$ & & \\
\hline Farmer & $93(15.27)$ & $72.40(17.91)$ & & \\
\hline Marital status & & & 9.84 & 0.002 \\
\hline$>¥ 5,000$ & 179 (29.39) & $66.60(24.21)$ & & \\
\hline Support of partner during pregnancy & & & 3.21 & 0.074 \\
\hline Very supportive & $562(92.28)$ & $69.99(21.07)$ & & \\
\hline Unsupportive & $47(7.72)$ & $75.66(17.73)$ & & \\
\hline Preferred route of delivery & & & 0.04 & 0.84 \\
\hline Vaginal delivery & $506(83.09)$ & $70.51(21.04)$ & & \\
\hline Cesarean section & $103(16.91)$ & $70.05(20.17)$ & & \\
\hline Relationship with partner & & & 4.89 & 0.008 \\
\hline Close & $346(56.82)$ & $68.33(22.26)$ & & \\
\hline Good & $227(37.27)$ & $72.55(18.93)$ & & \\
\hline General & $36(5.91)$ & $77.22(15.89)$ & & \\
\hline
\end{tabular}

Table 1 (continued) 
Table 1 (continued)

\begin{tabular}{|c|c|c|c|c|}
\hline Characteristics & $\mathrm{N}(\%)$ & Mean (SD) & $t$ or $\mathrm{F}$ & $P$ value \\
\hline No $<13$ & 438 (71.92) & $67.79(21.82)$ & & \\
\hline Yes $\geq 13$ & $171(28.08)$ & $77.17(16.47)$ & & \\
\hline Gestational age & & & 1.984 & 0.138 \\
\hline $28-36 \mathrm{~W}$ & $137(22.50)$ & $67.37(21.44)$ & & \\
\hline$>36 \mathrm{~W}$ & $401(65.84)$ & 71.47 (20.05) & & \\
\hline
\end{tabular}

FOC, fear of childbirth.

Table 2 Correlations between depression, social support, and FOC $(\mathrm{N}=609)$

\begin{tabular}{lccc}
\hline Variable (Scale) & Mean (SD) & EPDS & MSPSS \\
\hline EPDS & $9.50(5.19)$ & 1 & 1 \\
MSPSS & $70.91(9.25)$ & $-0.459^{\star *}$ & $-0.263^{* *}$ \\
W-DEQ & $70.43(20.88)$ & $0.302^{* *}$ & 1 \\
\hline
\end{tabular}

${ }^{*} \mathrm{P}<0.01$. FOC, fear of childbirth; SD, standard deviation; EPDS, Edinburgh Postnatal Depression Scale; MSPSS, Multidimensional Perceived Social Support Scale; W-DEQ, Wijma De-livery Expectancy/Experience Questionnaire.

with partner $(\mathrm{F}=4.89, \mathrm{P}=0.008)$, and depressive symptoms $(\mathrm{t}=25.85, \mathrm{P}=0.000)$.

No statistically significant differences among other characteristics were found, such as spouses' attitude towards pregnancy, expected delivery mode, or nationality group.

\section{Correlation between FOC, social support, and depressive symptoms during pregnancy}

It was found that women with prenatal depressive symptoms were defined by the cutoff of $\geq 13$ (Table 2). Participants' mean scores of social support and FOC were 70.90 (SD: 9.25 ) and 70.43 (SD: 20.88), respectively.

The Pearson's correlation analysis showed that having antenatal depressive symptoms correlated significantly negatively with social support $(\mathrm{r}=-0.459, \mathrm{P}<0.001)$ and correlated positively with FOC $(\mathrm{r}=0.302, \mathrm{P}<0.001)$, while social support was significantly negatively correlated with FOC $(\mathrm{r}=-0.263, \mathrm{P}<0.001)$ (Table 3).

\section{Mediation effect of social support in the relationship between prenatal depressive symptoms and FOC}

The results of the mediation effect analysis are shown in Table 3 and Figure 1. The results of the model are diagrammatically represented in Figure 1. Broadly, social support had a mediation effect between antenatal depression and FOC. Paths $a, b$, and $c$ manifest standardized coefficients among the paths. Path $c$ displays the link between antenatal depression and FOC; $a$ displays the link between antenatal depression and social support; $b$ demonstrates social support and FOC; and $c^{\prime}$ displays the effect of antenatal depression on FOC incorporating mediating social support.

Table 3 presents the significance test of the mediating pathways. The results of this study indicated that the correlation between FOC and depressive symptoms was partially mediated by social support ( $95 \%$ CI: 0.13 to 0.46 ), with an indirect effect $(a b=c-c)$ of social support of 0.29 , which comprised $23.87 \%$ of the total effect.

\section{Discussion}

This study showed that healthy nulliparous women with depressive symptoms were significantly and positively associated with FOC. This finding is consistent with previous studies $(6,33,53)$. Prenatal depression has been inferred as an independent risk factor for FOC. Social support was negatively related to depressive symptoms 
Table 3 The results of mediation analysis $(\mathrm{N}=609)$

\begin{tabular}{|c|c|c|c|c|c|c|c|c|}
\hline \multirow{2}{*}{ Path } & \multirow{2}{*}{ Coefficient } & \multirow{2}{*}{$S E$} & \multirow{2}{*}{$t$} & \multirow{2}{*}{$P$ value } & \multicolumn{4}{|c|}{$95 \% \mathrm{Cl}$} \\
\hline & & & & & LLCI & ULCI & $\mathrm{R}^{2}$ & $F(P)$ \\
\hline$C$ & 1.215 & 0.155 & 7.82 & 0.000 & 0.91 & 1.52 & 0.09 & $61.09^{\star *}$ \\
\hline$a$ & -0.817 & 0.064 & -12.72 & 0.000 & -0.94 & -0.69 & 0.21 & $161.90^{\star \star}$ \\
\hline$b$ & -0.355 & 0.097 & -3.65 & 0.000 & -0.55 & -0.16 & 0.11 & $37.83^{\star \star}$ \\
\hline Direct effect $(c)$ & 0.925 & 0.173 & 5.34 & 0.000 & 0.59 & 1.27 & - & - \\
\hline Indirect effect & 0.290 & 0.085 & - & - & 0.127 & 0.461 & - & - \\
\hline
\end{tabular}

${ }^{* \star} \mathrm{P}<0.01$. SE, standard error; $\mathrm{Cl}$, confidence interval; $\mathrm{LLCl}$, lower limit confidence interval; ULCI, upper limit confidence interval.

after potential covariates were controlled, revealing it as a protective factor against FOC. Social support was found to be vital for prevention of FOC, comprising $23.87 \%$ of the total effect between antenatal depression and FOC.

Additionally, the prevalence of antenatal depressive symptoms was $28.08 \%$, with 171 of the 609 participants displaying this quality. Life stress, lack of social support continued to be associated with antenatal depression (54). Several studies have shown that depressive/stress episodes occur more frequently during the first and third trimester of pregnancy, compared with the second $(55,56)$. The most vulnerable women are more likely to experience stress when they are coping with the new event of becoming mothers, and when they are about to deliver and start a new life (56). Interventions for prenatal and postpartum stress and/or anxiety to date include, but are not limited to, cognitive behavioural therapy (CBT), mindfulness, music, and exercise (57). Good preparedness for delivery could reduce depressive symptoms (20). Therefore, healthcare givers are encouraged to increase their knowledge and skills surrounding the treatment of pregnant women with depressive symptoms. Hence, further studies are required with a focus on customed interventions to minimize FOC among nulliparous women with depressive symptoms.

Social support, especially spousal support, is a key factor during pregnancy and the perinatal period (58), as it enables prenatal women to draw from social resources, helping them manage stress and anxiety more easily and prepare for their transition into motherhood (59). In our study, lower antenatal depression was found to be significantly negatively associated with higher levels of social support, which was similar to the findings of previous studies $(60,61)$. This finding was verified by a reduction in mean EPDS scores accompanied by a rise in MSPSS scores. Expressly, the more perceived social support improved, the more psychological problems caused by stressful life events were reduced.

The prevalence of high FOC (scores 66-84) and severe FOC $(\geq 85)$ in nulliparous women in this study was $45.5 \%$ and $22.3 \%$ respectively. Severe FOC was much higher than in Ireland (7.4\%) (62), and similar with previous Asian population studies (25\%) (5).

Social support was significantly and inversely associated with FOC. Higher levels of social support were associated with lower FOC. Lack of family and social support has been found to increase FOC, which is in line with the finding in this study $(4,5,12,30,63-65)$. Pregnant women of lower socio-economic status with limited family support may have diminished access to resources and decreased ability to obtain relevant information, either from antenatal care staff or online resources. Insufficient knowledge of the delivery process may have resulted in the higher degree of FOC in this study.

More importantly, it was revealed that social support could act as a mediator between depressive symptoms and FOC in nulliparous women. Nulliparous women with depressive symptoms who received more social support could experience more confidence when preparing birth, compared with women receiving less social support. This finding suggested a possible mediating effect of social support on the relationship between antenatal depression and FOC for nulliparous women.

Interestingly, previous studies have emphasized on the impact of improving social support to reduce depressive symptoms $(66,67)$, while this study found that a higher level of depressive symptoms may lead to poorer social support and further give rise to severe levels of FOC. These findings suggested that we may reduce the FOC in pregnant women by addressing lowering the level of depressive symptoms and/or enhancing the level of social support. Women could be high self-esteem and high self-efficacy 
with adequate partner/social support and satisfaction in the marital relationship, thereby overcoming the difficulties experienced in the transition to parenthood, protecting maternal mental health (20).

Social support is associated with FOC in pregnant women, and assists in strengthening women's sense of self-efficacy, which might further decrease the number of elective cesareans. Hildingsson et al. (68) found that women who felt they were in control of their bodies and were wellinformed about the process of labor were more likely to show a decrease in or elimination of fear symptoms. The fact that social support mediated the correlation between antenatal depression and FOC implies in part that strengthening social support for women with depressive symptoms may decrease their FOC. It is helpful for nulliparous women to obtain guidance and support from women who have prior experience with bearing children, including mothers, sisters, family members, and friends. Support can also come from healthcare professionals such as obstetricians, midwives, or psychologists.

Nonetheless, it is worth mentioning that depressive symptoms did have a remarkably direct impact on FOC, manifesting that social support was only a partial mediator and other variables might have been overlooked in this study.

\section{Conclusions}

Perceived social support played a mediating role between depressive symptoms and FOC among healthy pregnant women. Solutions and suggestions to improve social support are anticipated to have a positive effect on reducing depressive symptoms for pregnant women with FOC.

\section{Limitations}

This study had some inescapable limitations, which could be improved in further researches. This study only collected small scale samples from 2 hospitals in Xi'an, China. In the future, the sample size could be increased to conduct further studies in different regions of China. Further analysis could be made from the perspectives of economic level, health literacy, and cultural background to encompass the diversity in status of economic, cultural, and characteristic regional differences. Above all, this crosssectional study did not allow us to extrapolate a causal relationship among depressive symptoms, social support, and FOC. Additionally, variables in this study were assessed by self-report questionnaires, which might overstate the symptoms of depression or FOC. In addition, self-report questionnaire is limited for pregnant participants to state their personal feelings or information that was omitted, which could be supplemented in interviews in further studies. Finally, only low risk nulliparous women in the second and/or third trimester were recruited and involved in this study. It is recommended to consider examining high risk and multiparous women in their first trimester in further studies.

\section{Acknowledgments}

Funding: None.

\section{Footnote}

Reporting Checklist: The authors have completed the COREQ reporting checklist. Available at http://dx.doi. org/10.21037/apm-21-854

Data Sharing Statement: Available at http://dx.doi. org/10.21037/apm-21-854

Conflicts of Interest: All authors have completed the ICMJE uniform disclosure form (available at http://dx.doi. org/10.21037/apm-21-854). The authors have no conflicts of interest to declare.

Ethical Statement: The authors are accountable for all aspects of the work in ensuring that questions related to the accuracy or integrity of any part of the work are appropriately investigated and resolved. The ethics review was approved by the Ethics Committee of Xi'an Medical University (XYLS2018170) before the survey. The participants provided written informed consent prior to commencement of the study. All procedures performed in this study involving human participants were in accordance with the Declaration of Helsinki (as revised in 2013).

Open Access Statement: This is an Open Access article distributed in accordance with the Creative Commons Attribution-NonCommercial-NoDerivs 4.0 International License (CC BY-NC-ND 4.0), which permits the noncommercial replication and distribution of the article with the strict proviso that no changes or edits are made and the original work is properly cited (including links to both the formal publication through the relevant DOI and the license). 
See: https://creativecommons.org/licenses/by-nc-nd/4.0/.

\section{References}

1. Ryding EL, Lukasse M, Parys AS, et al. Fear of childbirth and risk of cesarean delivery: a cohort study in six European countries. Birth 2015;42:48-55.

2. Wax JR, Cartin A, Pinette MG, et al. Patient Choice Cesarean: An Evidence-Based Review. Obstet Gynecol Surv 2004;59:601-16.

3. Hofberg, K, Ward M. Tokophobia: A Profound Dread and Avoidance of Childbirth (When Pathological Fear Effects the Consultation. In: Cockburn J, Pawson ME, editors. Psychological challenges in obstetrics and gynecology: The clinical management. New York, NY: Springer Science + Business Media, 2007:165-72.

4. Toohill J, Creedy DK, Gamble J, et al. A cross-sectional study to determine utility of childbirth fear screening in maternity practice - An Australian perspective. Women Birth 2015;28:310-6.

5. O'Connell MA, Leahy-Warren P, Khashan AS, et al. Worldwide prevalence of tocophobia in pregnant women: systematic review and meta-analysis. Acta Obstet Gynecol Scand 2017;96:907-20.

6. Räisänen S, Lehto SM, Nielsen HS, et al. Fear of childbirth in nulliparous and multiparous women: a population-based analysis of all singleton births in Finland in 1997-2010. BJOG 2014;121:965-970.

7. Laursen M, Johansen C, Hedegaard M. Fear of childbirth and risk for birth complications in nulliparous women in the Danish National Birth Cohort. BJOG 2009;116:1350-5.

8. Nystedt A, Högberg U, Lundman B. The negative birth experience of prolonged labour: a case-referent study. J Clin Nurs 2005;14:579-86.

9. Van den Bergh BRH, Mulder EJH, Mennes M, et al. Antenatal maternal anxiety and stress and the neurobehavioural development of the fetus and child: links and possible mechanisms. A review. Neurosci Biobehav Rev 2005;29:237-58.

10. Nilsson C, Bondas T, Lundgren I. Previous Birth Experience in Women With Intense Fear of Childbirth. J Obstet Gynecol Neonatal Nurs 2010;39:298-309.

11. Eberhard-Gran M, Slinning K, Eskild A. Fear during labor: the impact of sexual abuse in adult life. J Psychosom Obstet Gynaecol 2008;29:258-61.

12. Laursen M, Hedegaard M, Johansen C, et al. Fear of childbirth: predictors and temporal changes among nulliparous women in the Danish National Birth Cohort. BJOG 2008;115:354-60.

13. Saisto T, Salmela-Aro K, Nurmi JE, et al. Psychosocial characteristics of women and their partners fearing vaginal childbirth. BJOG 2001;108:492-8.

14. Roomruangwong C, Kanchanatawan B, Sirivichayakul $\mathrm{S}$, et al. Antenatal depression and hematocrit levels as predictors of postpartum depression and anxiety symptoms. Psychiatry Res 2016 Apr;238:211-7.

15. Gentile S. Untreated depression during pregnancy: Shortand long-term effects in offspring. A systematic review. Neuroscience 2017;342:154-66.

16. Yin $X$, Sun N, Jiang N, et al. Prevalence and associated factors of antenatal depression: Systematic reviews and meta-analyses. Clin Psychol Rev 2021;83:101932.

17. Mu TY, Li YH, Pan HF, et al. Postpartum depressive mood (PDM) among Chinese women: a meta-analysis. Arch Womens Ment Health 2019;22:279-87.

18. Chi $\mathrm{X}$, Zhang $\mathrm{P}, \mathrm{Wu} \mathrm{H}$, et al. Screening for Postpartum Depression and Associated Factors Among Women in China: A Cross-Sectional Study. Front Psychol 2016;7:1668.

19. Andersson L. Neonatal Outcome following Maternal Antenatal Depression and Anxiety: A Population-based Study. Am J Epidemiol 2004;159:872-81.

20. Zeng Y, Cui Y, Li J. Prevalence and predictors of antenatal depressive symptoms among Chinese women in their third trimester: a cross-sectional survey. BMC Psychiatry 2015;15:66.

21. Biaggi A, Conroy S, Pawlby S, et al. Identifying the women at risk of antenatal anxiety and depression: A systematic review. J Affect Disord 2016;191:62-77.

22. Xie RH, He G, Koszycki D, et al. Prenatal Social Support, Postnatal Social Support, and Postpartum Depression. Ann Epidemiol 2009;19:637-43.

23. Li Y, Long Z, Cao D, et al. Social support and depression across the perinatal period: A longitudinal study. J Clin Nurs 2017;26:2776-83.

24. Sperry DM, Widom CS. Child abuse and neglect, social support, and psychopathology in adulthood: A prospective investigation. Child Abuse Negl 2013;37:415-25.

25. Fisher J, Tran T, Duc Tran T, et al. Prevalence and risk factors for symptoms of common mental disorders in early and late pregnancy in Vietnamese women: A prospective population-based study. J Affect Disord 2013;146:213-9.

26. Lara MA, Navarro C, Navarrete L. Outcome results of a psycho-educational intervention in pregnancy to prevent PPD: A randomized control trial. J Affect Disord 
2010;122:109-17.

27. Barrera M. Distinctions between social support concepts, measures, and models. Am J Commun Psychol 1986;14:413-45.

28. Cobb S. Social Support as a Moderator of Life Stress. Psychosom Med 1976;38:300-14.

29. Guruge S, Thomson MS, George U, et al. Social support, social conflict, and immigrant women's mental health in a Canadian context: a scoping review. J Psychiatr Ment Health Nurs 2015;22:655-67.

30. Elvander C, Cnattingius S, Kjerulff KH. Birth experience in women with low, intermediate or high levels of fear: Findings from the first baby study. Birth 2013;40:289-96.

31. Lukasse M, Schei B, Ryding EL. Prevalence and associated factors of fear of childbirth in six European countries. Sex Reprod Healthc 2014;5:99-106.

32. Khwepeya M, Lee GT, Chen SR, et al. Childbirth fear and related factors among pregnant and postpartum women in Malawi. BMC Pregnancy Childbirth 2018;18:391.

33. Toohill J, Fenwick J, Gamble J, et al. Psycho-Social Predictors of Childbirth Fear in Pregnant Women: An Australian Study. Open J Obstet Gynecol 2014;04:531-43.

34. Saisto T, Halmesmäki E. Fear of childbirth: a neglected dilemma. Acta Obstet Gynecol Scand 2003;82:201-8.

35. Rouhe H, Salmela-Aro K, Halmesmäki E, et al. Fear of childbirth according to parity, gestational age, and obstetric history. BJOG 2009;116:67-73.

36. Räisänen S, Lehto SM, Nielsen HS, et al. Risk factors for and perinatal outcomes of major depression during pregnancy: a population-based analysis during 2002-2010 in Finland. BMJ Open 2014;4:e004883.

37. Dencker A, Nilsson C, Begley C, et al. Causes and outcomes in studies of fear of childbirth: A systematic review. Women and Birth 2019;32:99-111.

38. Turner RJ, Grindstaff CF, Phillips N. Social Support and Outcome in Teenage Pregnancy. J Health Soc Behav 1990;31:43.

39. Collins NL, Dunkel-Schetter C, Lobel M, et al. Social support in pregnancy: psychosocial correlates of birth outcomes and postpartum depression. J Pers Soc Psychol 1993;65:1243-58.

40. Rising SS. Centering pregnancy. An interdisciplinary model of empowerment. J Nurse Midwifery 1998;43:46-54.

41. Sjögren B. Fear of childbirth and psychosomatic support. A follow up of 72 women. Acta Obstet Gynecol Scand 1998;77:819-25.

42. Fisher C, Hauck Y, Fenwick J. How social context impacts on women's fears of childbirth: A Western Australian example. Soc Sci Med 2006;63:64-75.

43. Leigh B, Milgrom J. Risk factors for antenatal depression, postnatal depression and parenting stress. BMC Psychiatry 2008;8:24.

44. Fenwick J, Toohill J, Creedy DK, et al. Sources, responses and moderators of childbirth fear in Australian women: A qualitative investigation. Midwifery 2015;31:239-46.

45. Cox JL, Holden JM, Sagovsky R. Detection of Postnatal Depression. Br J Psychiatry 1987;150:782-6.

46. Lee DTS, Yip SK, Chiu HFK, et al. Detecting postnatal depression in Chinese women. Br J Psychiatry 1998;172:433-7.

47. Zimet GD, Dahlem NW, Zimet SG, et al. The Multidimensional Scale of Perceived Social Support. J Pers Assess 1988;52:30-41.

48. Wijma K, Wijma B, Zar M. Psychometric aspects of the W-DEQ; a new questionnaire for the measurement of fear of childbirth. J Psychosom Obstet Gynaecol 1998;19:84-97.

49. Toohill J, Fenwick J, Gamble J, et al. Prevalence of childbirth fear in an Australian sample of pregnant women. BMC Pregnancy Childbirth 2014;14:275.

50. Liu SS,Liu JE. Investigation on the status and influencing factors of childbirth fear of pregnant women in Beijing area. Chinese J Mod Nurs Nurs 2015;21:997-1000.

51. Hayes AF. Introduction to mediation, moderation and con- ditional processanalysis: A regression-based approach. Guilford Publications; 2017.

52. Hayes AF, Rockwood NJ. Regression-based statistical mediation and moderation analysis in clinical research: Observations, recommendations, and implementation. Behav Res Ther 2017;98:39-57.

53. Tsui MH, Pang MW, Melender HL, et al. Maternal fear associated with pregnancy and childbirth in Hong Kong Chinese women. Women Health 2006;44:79-92.

54. Woods SM, Melville JL, Guo Y, et al. Psychosocial stress during pregnancy. Am J Obstet Gynecol 2010;202:61.e1-7.

55. Lee AM, Lam SK, Sze Mun Lau SM, et al. Prevalence, Course, and Risk Factors for Antenatal Anxiety and Depression. Obstet Gynecol 2007;110:1102-12.

56. Marchesi C, Bertoni S, Maggini C. Major and Minor Depression in Pregnancy. Obstet Gynecol 2009;113:1292-8.

57. Alderdice F, McNeill J, Lynn F. A systematic review of systematic reviews of interventions to improve maternal mental health and well-being. Midwifery 2013;29:389-99.

58. Alio AP, Lewis CA, Scarborough K, et al. A community perspective on the role of fathers during pregnancy: a 
qualitative study. BMC Pregnancy Childbirth 2013;13:60.

59. Highet N, Stevenson AL, Purtell C, et al. Qualitative insights into women's personal experiences of perinatal depression and anxiety. Women and Birth 2014;27:179-84.

60. Zhong Y, Wang J, Nicholas S. Social support and depressive symptoms among family caregivers of older people with disabilities in four provinces of urban China: the mediating role of caregiver burden. BMC Geriatr 2020;20:3.

61. Faramarzi M, Pasha H. The Role of Social Support in Prediction of Stress During Pregnancy. J Babol Univ Med Sci 2015;17:52-60.

62. O'Connell MA, Leahy-Warren P, Kenny LC, et al. The prevalence and risk factors of fear of childbirth among pregnant women: A cross-sectional study in Ireland. Acta Obstet Gynecol Scand 2019;98:1014-23.

63. Takegata M, Haruna M, Matsuzaki M, et al. Antenatal fear of childbirth and sense of coherence among healthy pregnant women in Japan: A cross-sectional study. Arch

Cite this article as: Zhou XL, Liu H, Li XH, Li F, Zhang SM, Zhang SR. Mediating effects of social support between antenatal depression and fear of childbirth among nulliparous woman. Ann Palliat Med 2021;10(6):6399-6409. doi: 10.21037/ apm-21-854
Womens Ment Health 2014;17:403-9.

64. Zheng DD, Zhou LH, Wu XL, et al. Fear of childbirth in primiparas during the late stages of pregnancy and its influencing factors. Matern Child Heal Care China 2018;33:3525-8.

65. Wei J, Liu JY, Wu YP, et al. Investigation of fear of childbirth and its influencing factors. J Nurs Sci (Chinese) 2016;31:86-9.

66. Milgrom J, Hirshler Y, Reece J, et al. Social Support-A Protective Factor for Depressed Perinatal Women? Int J Environ Res Public Health 2019;16:1426.

67. Rashid A, Mohd R. Poor social support as a risk factor for antenatal depressive symptoms among women attending public antennal clinics in Penang, Malaysia. Reprod Health 2017;14:144.

68. Hildingsson I, Nilsson C, Karlström A, et al. A Longitudinal Survey of Childbirth-Related Fear and Associated Factors. J Obstet Gynecol Neonatal Nurs 2011;40:532-43. 